\title{
Role of Parental Attitude in Development of Aggressive Behavior among Adolescents
}

\author{
Dr. Fareeda Shaheen ${ }^{1}$
}

\section{ABSTRACT:}

Purpose of the present investigation was to study the role of parental attitude in development of aggressive behavior among adolescents. The sample comprised of 200 (100 male and 100 female) undergraduate students of Aligarh Muslim University Aligarh. Parent-Child Relation Questionnaire (PCRQ) (Singh, 1984) was used for measuring parental attitude and Aggression Questionnaire (Buss \& Perry, 1992) was used for measuring adolescents aggression. Pearson Product-Moment Correlation and t-test were used for analyzing the data. Result revealed that there was significant negative correlation between positive parental attitude and aggression. It was also found that there was significant positive correlation between negative parental attitude and aggression. When gender differences was conducted on same sample, it was found that in father's attitude, female students scored significantly higher on only one positive dimension of father's attitude i.e. disciplining out of three positive dimensions (i.e. loving, protecting and disciplining) in comparison to male students, while male students scored significantly higher on only one negative dimension of father's attitude i.e. punishing out of three negative dimensions (i.e. dominating, rejecting, and punishing) in comparison to female students. Similarly, in mother's attitude, the results revealed that female students also scored significantly higher on two positive dimension of mother's attitude (i.e. loving and disciplining) out of three positive dimensions in comparison to male students. The results also showed that male students scored significantly higher on all three negative dimension of mother's attitude in comparison to female students. Further it was found that male students scored significantly higher on all four dimensions of aggression (i.e. physical, verbal, anger and hostility) in comparison to female students.

Keywords: Parental Attitudes, Aggression, Adolescents.

\section{Aggression}

The problem of aggression among adolescents is a common mental health issue of present era and interesting research topic for many psychologists.

${ }^{1}$ Post-Doctoral Fellow (PDF-ICSSR) Dept. of Psychology, A.M.U. Aligarh

(C) 2015 I F Shaheen; licensee IJIP. This is an Open Access Research distributed under the terms of the Creative Commons Attribution License (http://creativecommons.org/licenses/by/2.0), which permits unrestricted use, distribution, and reproduction in any Medium, provided the original work is properly cited. 
The increment in adolescent aggressive behavior during the last decade has intensified the search for predictors of aggressive behaviors. Psychologists are more concerned about the nature, causal factors, severity and the therapeutic approaches for controlling and preventing aggressive behaviors. Aggression is a form of behavior characterized by physical and verbal attack. It may appear either appropriate or self-protected even constructive as in healthy self assertiveness or inappropriate and destructive. Aggression may be directed outward against others or inward, against the self, leading to self-destructive or suicidal actions. It may be driven by emotional arousal often some form of frustration, or it may be instrumental, when it is used to secure a reward.

It is found that over the last few years, aggression and violence levels have drastically increased among adolescents and young adults (Paternite, Simons, \& Shore, 2001). The National Center for Education Statistics (National Center for Education Statistics, 2006) reported that 36\% of students in grades 9-12 had been in at least one physical fight during the year 2005, which had increased from 33\% in 2003. Moreover, from 1985 to 1991, homicide rates increased $154 \%$ among 15-19 year-olds (Dahlberg, 1998). A Cross-sectional study was conducted by Sharma, Grover, and Chaturvedi (2008) in South Delhi, India, in which they assessed risk behavior related to interpersonal violence and its epidemiological relationship among 550 adolescents of various schools and colleges aged 14-19 years. Their study revealed that, 65 (11.8\%) carrying a weapon in past 30 days, $74(13.5 \%)$ had threatened or injured someone with a weapon and almost one in every two boys $(49.1 \%)$ reported being involved in a physical fight in past 12 months. They also found significant correlation between interpersonal violence and male gender, lower age, and number of close friends (Frick, \& Silverthorn, 2001).

Not surprisingly, an increasing number of children are being referred to mental health services for treatment of their aggressive and antisocial behaviors (Hawkins, Herrenkohl, Farrington, Brewer, Catalano, \& Harachi, 1998). It is difficult to isolate an explanation for this increase; however researchers have been able to identify a variety of factors that correlate with aggressive behaviors. Understanding how aggressive behaviors manifest is complex because of the many factors involved such as parental attitudes, family factor, school environment, social factor, personal beliefs and cognitive factor etc. For example, Hawkins et. al. (1998) found a strong correlation between juvenile aggression and child maltreatment, poor family management, family conflict, separation from home, and residential mobility.

\section{Parental Attitude}

There is research evidence suggesting that the parenting attitude play important role in development of aggressive behavior. Parenting attitude are the expressions of the values individuals have about raising children and include thoughts, beliefs, and judgments about child care (Holden, \& Buck, 2002). Parenting attitude can be negative or positive. It is found that those parents who have positive attitude show warmth, affection, approval and understanding toward their children, they are called accepting parents; while on the other hand those parents who are cold, disapproving and punitive toward their child. They do not enjoy their children nor are they 
sensitive to their needs, rejecting parents criticize, punish or ignore their children's physical and emotional needs even as limiting their expression of affection and approval. Such parents dislike, disapprove their children are called rejecting parents. Rejecting parents express their aggression physically by hitting, pushing, pinching and hurting the child, whereas verbal expression of anger involves sarcastic, cursing, shouting, humiliating, behaviors toward their child. All forms of these behaviors tend to include children to feel unloved or rejected, as a result such children develop usually aggressive and hostile behaviors (Kim, Yeong., \& Ge, 2000); (Young, Berenson, Cohen, \& Garcia, 2005).

Parents who are rated high on warmth show higher level of concern, involvement and affection toward their children. Warmth may be expressed behaviorally by the parent mainly in terms of higher levels of typical warm behavior e.g., showing more active concern, caretaking and playful joking behavior. All kinds of nurturing, supportive and loving, behaviors are expressions of parental acceptance. On the basis of large number of studies on children's perceptions of parental behavior internationally psychologists suggested that the warmth dimension is more important in the positive development of children (McCauley, Pavlidis, \& Kendall, 2001).

Some research suggests that child characteristics such as noncompliance and aggressiveness have been associated with negative parent-child relationships and parenting attitudes (Florsheim, Tolan, \& Gorman-Smith, 1998). However, child characteristics are less likely to influence parenting attitudes when the child is of preschool age. When the child is at a young age, parenting attitudes are most likely to reflect perceptions that the parent developed through their personal experiences, such as early childhood experiences and stressful life events (Gerra, Angioni, Zaimovic, Moi, Bussandri, \& Bertacca, 2004). Other studies in the child maltreatment literature have shown that negative parenting attitude, such as a disregard for a child's needs, displeasure in the parenting role, and the belief that one's children intentionally annoy you, strengthen the likelihood of poor parenting behaviors within single-mother families. Such type of negative attitude of parents lead to develop more mental health problems such as anxiety, depression and more negative behavior like drug abuse, delinquency, and aggression among adolescents (Muris, Meesters, Schouten, \& Hoge, 2004); (Wood, Read, Mitchell, \& Brand, 2004).

It was found that the influence of family play important role in development of antisocial behavior among male adolescents, (Larzelere Patterson, 1990); (Farrington, 1995). Different theoretical approaches have focused on the role of family factors in development of aggressive behavior among adolescents, such as social learning theory suggested that parents act as models for violent behaviors that children observe and then imitate. A second theoretical approach emphasizes that aggression emerges as a reaction to unsatisfactory and frustrating relationships with significant others, especially the attachment object, parent child relationship, parental attitudes etc. (Shaw \& Bell, 1993). According to Gottfredson and Hirschi' (1990) aggression is caused by low self-control. The major source of low self control is ineffective child rearing, it may be negative parental attitude, low parental supervision, parental support for aggression, punishment for aggressive behaviors, and poor relationship with the parents. 
It is found in various researches that parental monitoring has been inversely associated with antisocial behavior, drug use, tobacco use, and early sexual activity (Patterson, Baryshe Ramsey, 1989; Steinberg, Fletcher, Darling 1994; Biglan, Duncan, Ary, Smolkowski,1995; Metzler, Neoll, Biglan, Ary, Smolkowski, 1994). Low parental monitoring and poor discipline have also been found to correlate significantly with delinquency among 7th- and 10th-grade boys, and to predict delinquency in 4th-grade boys who were followed through 7th grade (Patterson, Stouthamer-Loeber, 1984). The more removed from parental supervision the adolescent is, the more he or she becomes susceptible to peer influences to engage in violence and other healthcompromising behaviors (Steinberg, 1990). Parental communication about behaviors is another parenting practice influencing aggressive behaviors. According to social cognitive theory aggressive behaviors are learned through modeling and reinforcement and parents are model for their children but some times they praise aggressive peer interactions and various high-risk practices such as fighting or "acting tough" (Bandura, 1986). Parents may have considerable influence in development of their children's risk behaviors by their communications about those behaviors (Cohen, Richardson, LaBree,1994). While, positive parental attitude, Parental disapproval of aggressive behaviors, combined with parental monitoring and a positive parent child relationship play important role in increasing child's self-control, reducing the likelihood of aggression and delinquency (Gottfredson, Hirschi, 1990) Parenting styles may be reflected in children's assessments of how well they get along with their parents (Baumrind, 1991). Adolescents who feel close to their parents consistently show more positive psychosocial development, behavioral competence, and psychosocial wellbeing (Steinberg, 1986). A study of 5th- and 7th-grade boys and girls showed that the child's perception of positive relations with parents was associated with less disruptive behaviors, less substance use, and less association with deviant peers (Cohen, Richardson, LaBree, 1994). Vissing, Straus, Gelles, and Harrop, (1991) in a national representative sample of parents with children under 18, found higher levels of physical aggression, delinquency, and interpersonal problems among both boys and girls who had experienced verbal aggression from the parents in the form of swear words and insults. Another national study of middle and high school students showed that violence is inversely associated with parent-family connectedness, and that this association was stronger among middle school students than high school students (Resnick et. a., 1997).

It was also found that adolescents who were members of families that were less supportive, discouraging and have negative parent-child relationships, experience more anxiety, depression and developed maladaptive behaviors such as aggression, delinquent behaviors and substance use in comparison to adolescents who were members of families that were supportive, and foster positive parent-child relationships (Florsheim, Tolan, \& Gorman-Smith, 1998); (Gerra, Angioni, Zaimovic, Moi, Bussandri, \& Bertacca, 2004). Psychologists also emphasized that poor family functioning has a negative effect on adolescent outcomes (Muris, Meesters, Schouten, \& Hoge, 2004). Therefore the aim of present investigation is to study the role of parental attitude in development of aggressive behavior among adolescents. 
OBJECTIVES OF THE STUDY: Following objectives were formulated for the present study:

1. To find out the relationship between different types of father's attitude and aggressive behavior.

2. To find out the relationship between different types of mother's attitude and aggressive behavior.

3. To find out the significance of difference between male and female students on father's attitude.

4. To find out the significance of difference between male and female students on mother's attitude.

5. To find out the significance of difference between male and female students on aggression.

\section{METHOD}

Participants: Sample of the present research paper comprised of 200 (100 male and 100 female) undergraduate students from Aligarh Muslim University Aligarh. The random sampling technique was used for collecting data. Age of the subjects ranged between 19 to 21 years, the mean age being 20.5 years. All the students belonged to upper middle class socio-economic background.

Instruments: The following questionnaires and tests were administered on the participants for the study.

1. Parental Attitudes Scale: In order to assess the parental attitudes or child rearing style, parentchild relation questionnaire (PCRQ) developed by Singh (1984) was used. The PCRQ consists of two forms labeled as F-form (father form) and M-form (mother form). Each form has six subscales i.e. loving, dominating, rejecting, protecting, punishing and disciplining. Out of these six dimensions of parental attitudes, three dimensions or subscale are positive (i.e. loving, protecting and disciplining) and other three dimensions or subscale are negative .(i.e. dominating, rejecting and punishing). There are 10 items in each subscale with a total of 60 items. Three response categories i.e. 'yes', 'no' and 'doubtful', have been provided against each question. A score of 3, 1 and 2 have been assigned for each positively worded question for yes, no, and doubtful categories respectively. In case of negative items the order is reversed as $1,3, \&$ 2 respectively. Thus a maximum possible score on each scale is 30 and minimum 10 for both $\mathrm{F}$ form and $\mathrm{M}$ form. Split half reliability coefficients for different dimensions on both the forms ranged between .75 to .85 . The test- retest reliability coefficients ranged between .55 to .68 .

2. Aggression Questionnaire: The Aggression Questionnaire (Buss, \& Perry, 1992) was used for measuring adolescents aggressive behavior. It contains 29 self-report Likert-type items (e.g., "'I tell my friends openly when I disagree with them', 'Given enough provocation, I may hit another person'") assessing cognitive, affective, and behavioral components of this domain. Subscales include Hostility (i.e., hostile cognition), Anger (i.e., hostile affect), Physical aggression, and Verbal aggression. Correlations among components range from .25 
to .48. The factor structure of the AQ has been replicated in several confirmatory analyses (Buss, \& Perry, 1992). Its internal consistencies was ranging from .53 to .85.

Analysis: Product Moment Correlation and t-test were used to analyze the data.

\section{RESULTS}

Table: 1. Correlation between Parental Attitude and Aggression.

\begin{tabular}{|c|c|c|c|c|}
\hline \multirow[t]{2}{*}{ Father's Attitude } & \multicolumn{3}{|c|}{ Aggression } & \multirow[b]{2}{*}{ Hostility } \\
\hline & Physical & Verbal & Anger & \\
\hline Loving & $-.320 * *$ & $-.433 * *$ & $-.383 * *$ & $-.368 * *$ \\
\hline Dominating & $141 *$ & $278 * *$ & $241 * *$ & $281 * *$ \\
\hline Rejecting & $295 * *$ & $283 * *$ & $261 * *$ & $318 * *$ \\
\hline Protecting & $-275 * *$ & $-344 * *$ & $-354 * *$ & $-338 * *$ \\
\hline Punishing & $287 * *$ & $309 * *$ & $305 * *$ & $342 * *$ \\
\hline Disciplining & $-169 *$ & -107 & -130 & $-181 *$ \\
\hline \multicolumn{5}{|l|}{ Mother's Attitude } \\
\hline Loving & $-522 * *$ & $-613 * *$ & $-607 * *$ & $-590 * *$ \\
\hline Dominating & $230 * *$ & $313 * *$ & $307 * *$ & $340 * *$ \\
\hline Rejecting & $354 * *$ & $458 * *$ & $447 * *$ & $521 * *$ \\
\hline Protecting & $-389 * *$ & $-486 * *$ & $-482 * *$ & $-452 * *$ \\
\hline Punishing & $231 * *$ & $257 * *$ & $293 * *$ & $320 * *$ \\
\hline Disciplining & $-147 *$ & $-165 *$ & -113 & $-146^{*}$ \\
\hline
\end{tabular}

From the above table it is found that there is significant negative correlation between father's positive attitude and aggression. In other words, there is a significant negative correlation between two positive dimensions (i.e. loving and protecting) of fathers attitudes out of three positive dimensions (i.e. loving, protecting and disciplining) and different dimensions of aggression (i.e. physical, verbal, anger and hostility) scores. While third positive dimension of father's attitude (i.e. disciplining) was significantly negatively correlated with only two 
dimension of aggression i.e. physical and hostility out of four dimension (i.e. physical, verbal, anger and hostility). It is also observed from the table that there is a significant positive correlation between all three negative dimensions (i.e. dominating, rejecting and punishing) of fathers negative attitude and different dimensions of aggression (i.e. physical, verbal, anger and hostility) scores.

Similarly, it is also found that there is significant negative correlation between all two positive dimensions of mother's attitude (i.e. loving and protecting) and different dimensions of aggression (i.e. physical, verbal, anger and hostility) scores. While third positive dimension of mother's attitude (i.e. disciplining) was negatively correlated with three dimensions of aggression i.e. physical, verbal and hostility out of four dimension (i.e. physical, verbal, anger and hostility).

It is also apparent from the table that there is a strong significant positive correlation between all three negative dimensions (i.e. dominating, rejecting and punishing) of mothers negative attitude and all dimensions (i.e. physical, verbal, anger and hostility) of aggression.

Table-2: Comparison of Male and Female Students on Different dimensions of Parental Attitude and Aggression Scores. N=200 (Male-100, Female-100).

\begin{tabular}{|c|c|c|c|c|c|c|}
\hline Variables & Group & Mean & S.D. & t-value & df & Sig. \\
\hline \multicolumn{7}{|c|}{ Father's Attitude } \\
\hline \multirow{2}{*}{ Loving } & Male & 24.32 & 4.18 & \multirow{2}{*}{.65} & \multirow{2}{*}{198} & \multirow{2}{*}{ NS } \\
\hline & female & 23.95 & 3.17 & & & \\
\hline \multirow{2}{*}{ Dominating } & Male & 21.14 & 4.89 & \multirow{2}{*}{.15} & \multirow{2}{*}{198} & \multirow{2}{*}{ NS } \\
\hline & Female & 21.04 & 4.01 & & & \\
\hline \multirow{2}{*}{ Rejecting } & Male & 25.12 & 5.19 & \multirow{2}{*}{1.94} & \multirow{2}{*}{198} & \multirow{2}{*}{ NS } \\
\hline & Female & 23.71 & 5.06 & & & \\
\hline \multirow{2}{*}{ Protecting } & Male & 22.94 & 3.77 & \multirow{2}{*}{.63} & \multirow{2}{*}{198} & \multirow{2}{*}{ NS } \\
\hline & Female & 23.27 & 3.56 & & & \\
\hline \multirow{2}{*}{ Punishing } & Male & 23.94 & 5.01 & \multirow{2}{*}{2.66} & \multirow{2}{*}{198} & \multirow{2}{*}{.01} \\
\hline & Female & 22.13 & 4.58 & & & \\
\hline Disciplining & Male & 18.20 & 4.04 & 2.62 & 198 & .01 \\
\hline
\end{tabular}


Role of Parental Attitude in Development of Aggressive Behavior among Adolescents

\section{Female $19.63 \quad 3.65$}

\section{Mother's Attitude}

\begin{tabular}{|c|c|c|c|c|c|c|}
\hline \multirow{2}{*}{ Loving } & Male & 22.81 & 4.45 & \multirow{2}{*}{2.90} & \multirow{2}{*}{198} & \multirow{2}{*}{.01} \\
\hline & Female & 24.54 & 3.95 & & & \\
\hline \multirow{2}{*}{ Dominating } & Male & 21.95 & 3.83 & \multirow{2}{*}{3.17} & \multirow{2}{*}{198} & \multirow{2}{*}{.01} \\
\hline & Female & 19.98 & 4.86 & & & \\
\hline \multirow{2}{*}{ Rejecting } & Male & 23.24 & 4.67 & \multirow{2}{*}{4.54} & \multirow{2}{*}{198} & \multirow{2}{*}{.01} \\
\hline & Female & 20.06 & 5.19 & & & \\
\hline \multirow{2}{*}{ Protecting } & Male & 22.24 & 4.21 & \multirow{2}{*}{.39} & \multirow{2}{*}{198} & \multirow{2}{*}{ NS } \\
\hline & Female & 22.46 & 3.75 & & & \\
\hline \multirow{2}{*}{ Punishing } & Male & 22.68 & 4.20 & \multirow{2}{*}{4.08} & \multirow{2}{*}{198} & \multirow{2}{*}{.01} \\
\hline & Female & 19.97 & 5.12 & & & \\
\hline \multirow{2}{*}{ Disciplining } & Male & 16.61 & 4.07 & \multirow{2}{*}{2.14} & \multirow{2}{*}{198} & \multirow{2}{*}{.05} \\
\hline & Female & 17.76 & 3.48 & & & \\
\hline
\end{tabular}

\begin{tabular}{|c|c|c|c|c|c|c|}
\hline Aggression & & & & & & \\
\hline \multirow[b]{2}{*}{ Physical } & Male & 27.08 & 7.20 & \multirow{2}{*}{3.50} & \multirow{2}{*}{198} & \multirow{2}{*}{.01} \\
\hline & Female & 23.85 & 5.76 & & & \\
\hline \multirow[b]{2}{*}{ Verbal } & Male & 26.07 & 7.55 & \multirow[b]{2}{*}{2.16} & \multirow[b]{2}{*}{198} & \multirow[b]{2}{*}{.05} \\
\hline & Female & 23.87 & 6.76 & & & \\
\hline \multirow[b]{2}{*}{ Anger } & Male & 28.52 & 7.94 & \multirow[b]{2}{*}{2.80} & \multirow[b]{2}{*}{198} & \multirow[b]{2}{*}{.01} \\
\hline & Female & 25.68 & 6.23 & & & \\
\hline \multirow[b]{2}{*}{ Hostility } & Male & 30.32 & 8.50 & \multirow[b]{2}{*}{3.90} & \multirow[b]{2}{*}{198} & \multirow[b]{2}{*}{.01} \\
\hline & Female & 25.92 & 7.41 & & & \\
\hline
\end{tabular}


Table-2 shows that there is a significant difference between male and female students on only one positive dimension of father's attitude i.e. disciplining out of three dimensions. In other words female students scored significantly higher on disciplining attitude of father as compared to male students. It is also apparent from the table that there is a significant difference between male and female students on only one negative dimension father's attitude i.e. punishing out of three dimensions. In other words, male students scored significantly higher on punishing attitude of father as compared to female students.

Similarly, the table also shows that there is a significant difference between male and female students on two positive dimensions of mother's attitude i.e. loving and disciplining out of three dimensions. In other words female students scored significantly higher on loving and disciplining attitude of mother as compared to male students. It is also apparent from the table that significant difference was found between male and female students on all three negative dimensions of mother's attitude i.e. dominating, rejecting and punishing. Male students scored significantly higher on all three negative dimensions of mother's attitude as compared to female students.

It is also apparent from above table that there is a significant difference between male and female students on all four dimensions of aggression i.e. physical, verbal, anger and hostility. In other words male students scored significantly higher on all dimensions of aggression as compared to female students.

\section{DICUSSION}

The first objective of the present study was to examine the relationship between parental attitude and aggression among undergraduate students. Positive parental attitude (both father and mother) play important role in adolescents positive growth and development as well as protecting them from different types of mental health problems like anxiety, depression, drug abuse, delinquency and aggressive behavior. The results of the study indicate that positive parental attitudes was negatively correlated with aggressive behavior of adolescents. This study is supported by the findings of the earlier study for example McCauley, Pavlidis, \& Kendall, (2001) found that positive parental attitude such as nurturing, supportive, loving and warmth behaviors of parents play more important role in positive development of children. Bean et. al. (2006), also found in their study that when youths feel that their parents are supportive, caring, and loving towards them they experience low level of depression.

While negative parental attitudes (both father and mother), on the other hand, may lead to more mental heath problem and aggressive behavior. In the present study negative parental attitudes was found to be positively correlated with aggression. This study is supported by a number of earlier studies (Kim, Yeong., \& Ge, 2000); (Young, Berenson, Cohen, \& Garcia, 2005). They found that negative parental attitude lead to more aggressive behavior among children, they also observed that those children who feel unloved or rejected and punished by their parent such children more develop aggressive and hostile behaviors. In a study Hawkins et. al. (1998) also 
found a strong correlation between juvenile aggression and child maltreatment, poor family management, family conflict, separation from home, and residential mobility.

The other objective of this study was to find out the gender differences in parental attitude and aggression among same sample. When gender differences was investigated on above sample, it was found

that female students scored significantly higher on only one positive dimension of father's attitude i.e. disciplining out of three dimensions as compared to male students. While, male students scored significantly higher on one negative attitude of father i.e. punishing out of three negative dimensions as compared to female students.

Similarly, the result also showed that female students scored significantly higher on two positive dimensions i.e. loving and disciplining attitude of mother out of three positive dimensions as compared to male students. Whereas, male students scored significantly higher on all three negative dimensions of mother's attitude i.e. dominating, rejecting and punishing as compared to female students.

On the basis of above results and discussion, it is apparent that parents (both father and mother) have more positive attitude towards their female students as compared to male students. Whereas, it was also clear that for male students, parental attitude (both father and mother) are more negative as compared to female students. One important finding of this study is that mother's positive attitudes are more important and significant effect on adolescents positive growth and development as well as it enhanced individuals mental health and wellbeing as compared to father's attitudes. Although, negative parental attitudes both father and mother are equally influence in development of negative behavior of adolescents. As, other important finding of this study is that mother's negative attitudes lead to more negative behavior like aggression of adolescents as compared to father's attitudes. This may be the reason that male students committed more aggressive behavior as compared to female students. Since, it was found in gender differences that male students scored significantly higher on all four dimensions of aggression i.e. physical, verbal, anger and hostility as compared to female students. This study is supported by earlier study (Bingham et. al., 2006). Sekuk; Rimfat and Ogbonna (2003) noted that until recently male adolescents were by far more involved in delinquent acts than female. In a study Okpako, (2004) and Otuadah (2006) found that boys with poor parental background and negative parental behavior became more school dropouts, committed more delinquent and aggressive behavior etc as compared to boys with strong family background and positive parental behavior.

\section{CONCLUSION}

On the basis of above results and discussion it is concluded that positive parental attitude (both father and mother) play important role in protecting individuals from different type of mental health problems and negative behavior like delinquency and aggression, as it was found in this 
study that positive parental attitudes was negatively correlated with aggression. While negative parental attitude (both father and mother) play a crucial role in developing aggressive behavior among adolescents, as it was found in present study that negative parental attitude was positively correlated with aggression. Similarly, it is also concluded on the above results and discussion that mother's attitude are more important in experienced of aggression among adolescents as compared to fathers attitude. As it is clear from this study that mothers negative attitudes play significant role in developing aggressive behavior among adolescents.

\section{REFERENCES}

1. Bandura A (1986). Social Foundations of Thought and Action: A Social Cognitive Theory. Englewood Cliffs, NJ, Prentice Hall,

2. Baumrind D (1991). Parenting styles and adolescent development, in Lerner R, Petersen AC, Brooks-Gunn J (eds.): The Encyclopedia of Adolescence. New York, Garland, pp. 746-758.

3. Bean, R. A., Barber, B. K., \& Crane, R. D. (2006). Parental support, behavioral control, and psychological control among African American youth: The relationships to academic grades, delinquency, and depression. Journal of Family Issues, 27, 1335-1355.

4. Biglan A, Duncan TE, Ary DV, Smolkowski K (1995). Peer and parental influences on adolescent tobacco use. J Behav Med 18:315-330.

5. Bingham, Raymond C; Shope, Jean T \& Raghunathan Trivellore (2006) Patterns of Traffic Offenses from Adolescent Licensure into Early Young Adulthood. 39, 35 -42.

6. Buss, A. H., \& Perry, M. (1992). The aggression questionnaire. Journal of Personality and Social Psychology, 63, 452-459.

7. Cohen DA, Richardson J, LaBree L (1994). Parenting behaviors and the onset of smoking and alcohol use: A longitudinal study. Pediatrics 94:368-375.

8. Cohen DA, Richardson J, LaBree L (1994). Parenting behaviors and the onset of smoking and alcohol use: A longitudinal study. Pediatrics 94:368-375.

9. Dahlberg, L. L. (1998). Youth violence in the United States: Major trends, risk factors, and prevention approaches. American Journal of Preventive Medicine, 14, 259-272.

10. Farrington DP (1995). The development of offending and antisocial behavior from childhood: Key findings from the Cambridge study in delinquent development. $J$ Child Psychol Psych 360:929- 964.

11. Florsheim, P., Tolan, P. H., \& Gorman-Smith, D. (1998). Family relationships, parenting practices, the availability of male family members, and the behavior of inner-city boys in single-mother and two-parent families. Child Development, 69, 1437-1447.

12. Florsheim, P., Tolan, P. H., \& Gorman-Smith, D. (1998). Family relationships, parenting practices, the availability of male family members, and the behavior of inner-city boys in single-mother and two-parent families. Child Development, 69, 1437-1447.

13. Frick, P. J., \& Silverthorn, P. (2001). Behavior disorders in children. In H. E. Adams and P. B. Sutker (Eds.) Comprehensive Handbook of Psychopathology, 3rd ed. (pp. 879-919). New York: Plenum.

14. Gerra, G., Angioni, L., Zaimovic, A., Moi, G., Bussandri, M., \& Bertacca, S. (2004). Substance abuse among high-school students: Relationships with temperament, personality traits, and parental care perception. Substance Use and Misuse, 39, 345-367. 
15. Gerra, G., Angioni, L., Zaimovic, A., Moi, G., Bussandri, M., \& Bertacca, S. (2004). Substance abuse among high-school students: Relationships with temperament, personality traits, and parental care perception. Substance Use and Misuse, 39, 345-367.

16. Gottfredson MR, Hirschi T (1990). A General Theory of Crime. Stanford, CA, Stanford University Press.

17. Hawkins, J. D., Herrenkohl, T., Farrington, D. P., Brewer, D., Catalano, R. F., \& Harachi, T. (1998). A review of predictors of youth violence. In Loeber and Farrington (Eds.). Serious and violent juvenile offenders: Risk factors and successful interventions (pp. 106146). California: Sage Publications.

18. Holden, G. W., \& Buck, J. L. (2002). Parental attitudes toward childrearing. In M.H. Bornstein (Eds.), Handbook of parenting (pp. 537-562). Mahwah, N.J.: Erlbaum.

19. Kim, S. Yeong., \& Ge, X. (2000). Parenting practices and adolescent depressive symptoms in Chinese American families. Journal of Family Psychology, 14(3), 420-435.

20. Kim, S. Yeong., \& Ge, X. (2000). Parenting practices and adolescent depressive symptoms in Chinese American families. Journal of Family Psychology, 14(3), 420-435.

21. Larzelere RE, Patterson GR (1990). Parental management: Mediator of the effect of socioeconomic status on early delinquency. Criminology 28:301-323,

22. McCauley, E., Pavlidis, K., \& Kendall, K. (2001). Developmental precursors of depression: The child and the social environment. In I. M. Goodyer (Ed.), The depressed child and adolescent, (46-78). Cambridge, UK: Cambridge University Press.

23. McCauley, E., Pavlidis, K., \& Kendall, K. (2001). Developmental precursors of depression: The child and the social environment. In I. M. Goodyer (Ed.), The depressed child and adolescent, (46-78). Cambridge, UK: Cambridge University Press.

24. Metzler CW, Neoll J, Biglan A, Ary D, Smolkowski K (1994). The social context for risky sexual behavior among adolescents. J Behav Med 17:419-438.

25. Muris, P., Meesters, C., Schouten, E., \& Hoge, E. (2004). Effects of perceived control on the relationship between perceived rearing behaviors and symptoms of anxiety and depression in nonclinical preadolescents. Journal of Youth and Adolescents, 33, 51-58.

26. Muris, P., Meesters, C., Schouten, E., \& Hoge, E. (2004). Effects of perceived control on the relationship between perceived rearing behaviors and symptoms of anxiety and depression in nonclinical preadolescents. Journal of Youth and Adolescents, 33, 51-58.

27. National Center for Education Statistics (2006). Indicators of School Crime and Safety: 2006. http:// nces.ed.gov/programs/crimeindicators/ind_12.asp.

28. Okpako, J. E. F (2004) Parenting the Nigerian Adolescents Towards Smooth Transition to Adulthood. In Contemporary Issue and Research in Adolescents (I. A. Nwazuoke; O. Bamgbose \& O. A. Morokola (Ed) Ibadan Omoade Printing Press pp 275 - 288.

29. Otuadah, C. E. (2006) Parental Behaviour and Peer Group Influence as Correlates of Delinquent Behaviour among Secondary School Students in Warri Metropolis. Unpublished M.Ed Thesis of Delsu, Abraka. 
30. Paternite, C. E., Simons, K. J., \& Shore, C. (2001). Quality of parent/adolescent attachment and aggression in young adolescents. Journal of Early Adolescence, 21, 182203.

31. Patterson GR, DeBaryshe BD, Ramsey E (1989). A developmental perspective on antisocial behavior. Am Psychologist 44:329-335.

32. Patterson GR, Stouthamer-Loeber M (, 1984). The correlation of family management practices and delinquency. Child Development 55:1299-1307.

33. Resnick MD, Bearman PS, Blum RW, Bauman KE, Harris KM, Jones J, Tabor J, Beuhring T, Sieving RE, ShewM, et al (1997). Protecting adolescents from harm: Findings from the national longitudinal study on adolescent health. JAMA 278:823-832.

34. Sekuk, R. T. Rimfat, D. Z and Ogbonna B. B (2003). Prevalence of Delinquent Behaviour among Adolescents: Implications for Counselling. The Behaviour problems of the Nigeria Child. A Publication of the Nigerian Society for Educational Psychologists (NISEP) Edited by R. Onwukwe Nnachi \& P. S. E. Ezeh pp. 59-68

35. Sharma R, Grover VL, Chaturvedi S. (2008). Risk behaviors related to inter-personal violence among school and college-going adolescents in south Delhi. Indian J Community Med 33(2):858. Available from: http://www.ncbi.nlm.nih.gov/pubmed?term=PMC2784632.

36. Shaw DS, Bell RQ (1993). Developmental theories of parental contributors to antisocial behavior. J Abnormal Child Psychol 21:493-518.

37. Singh, R.A. (1984). Perception of maternal and Paternal behaviours in secondary school students. Indian Journal of Psychology. 59.

38. Steinberg L (1986). Latch-key children and susceptibility to peer pressure: An ecological analysis. Developmental Psychol 22:433-439.

39. Steinberg L 1990). Autonomy, conflict and harmony in the family relationships, in Feldman SS, ElliottGR(eds.): At the Threshold: The Developing Adolescent. Cambridge, MA, Harvard University Press, pp. 255-276.

40. Steinberg L, Fletcher A, Darling N (1994). Parental monitoring and peer influences on adolescent substance use. Pediatrics 93:1060-1064.

41. Vissing YM, Straus MA, Gelles RJ, Harrop JW (1991).Verbal aggression by parents and psychosocial problems of children. Child Abuse \& Neglect 15:223-238.

42. Wood, M. D., Read, J. P., Mitchell, R. E., \& Brand, N. H. (2004). Do parents still matter? Parent and peer influences on alcohol involvement among recent high school graduates. Psychology of Addictive Behaviors, 18, 19-30.

43. Young, J. F., Berenson, K., Cohen, P., \& Garcia, J. (2005). The role of parent and peer support in predicting adolescent depression: A longitudinal community study. Journal of Research on Adolescence, 15(4), 407-423.

44. Young, J. F., Berenson, K., Cohen, P., \& Garcia, J. (2005). The role of parent and peer support in predicting adolescent depression: A longitudinal community study. Journal of Research on Adolescence, 15(4), 407-423. 